\title{
BMJ Open Factors influencing maternal health in indigenous communities with presence of traditional midwifery in the Americas: protocol for a scoping review
}

\author{
Iván Sarmiento (D) , ${ }^{1,2}$ Sergio Paredes-Solís (D) , ${ }^{3}$ Martin Morris, ${ }^{4}$ Juan Pimentel, ${ }^{1,2}$ \\ Anne Cockcroft, ${ }^{1}$ Neil Andersson ${ }^{1,3}$
}

To cite: Sarmiento I, ParedesSolís S, Morris M, et al. Factors influencing maternal health in indigenous communities with presence of traditional midwifery in the Americas: protocol for a scoping review. BMJ Open 2020;10:e037922. doi:10.1136/ bmjopen-2020-037922

- Prepublication history and additional material for this paper are available online. To view these files, please visit the journal online (http://dx.doi. org/10.1136/bmjopen-2020037922).

Received 21 February 2020 Revised 20 May 2020 Accepted 17 July 2020

\section{Check for updates}

(c) Author(s) (or their employer(s)) 2020. Re-use permitted under CC BY-NC. No commercial re-use. See rights and permissions. Published by BMJ.

${ }^{1}$ CIET-PRAM, Department of Family Medicine, McGill University, Montreal, Québec, Canada

${ }^{2}$ Grupo de Estudios en Sistemas Tradicionales de Salud (GESTS), Universidad del Rosario, Bogotá, Cundinamarca, Colombia

${ }^{3}$ Centro de Investigación de Enfermedades Tropicales (CIET), Universidad Autónoma de Guerrero, Acapulco, México ${ }^{4}$ Schulich Library of Physical Sciences, Life Sciences and Engineering, McGill University, Montreal, Québec, Canada

Correspondence to

Iván Sarmiento;

ivan.sarmiento@mail.mcgill.ca

\section{ABSTRACT}

Introduction Indigenous mothers often receive culturally unsafe services that do not fully respond to their needs. The objective of this scoping review is to collate and assess evidence that identifies factors, including the role and influence of traditional midwives, that affect maternal health in indigenous communities in the Americas. The results will map Western perspectives reflected in published and unpublished literature to indicate the complex network of factors that influence maternal outcomes. These maps will allow for comparison with local stakeholder knowledge and discussion to identify what needs to change to promote culturally safe care.

Methods and analysis A librarian will search studies with iterative and documented adjustments in CINAHL, Scopus, Latin American and Caribbean Health Sciences Literature (LILACS), MEDLINE, Embase and Google Scholar without any time restrictions, and use Google search engine for grey literature. Included studies will be empirical (quantitative, qualitative or mixed); address maternal health issues among indigenous communities in the Americas; and report on the role or influence of traditional midwives. Two researchers will independently screen and blindly select the included studies. The quality assessment of included manuscripts will rely on the Mixed Methods Appraisal Tool (MMAT). Two independent researchers will extract data on factors promoting or reducing maternal health in indigenous communities, including the role or influence of traditional midwives. Fuzzy cognitive mapping will summarise the findings as a list of relationships between identified factors and outcomes with weights indicating strength of the relationship and the evidence supporting this.

Ethics and dissemination This review is part of a proposal approved by the ethics committees at McGill University and the Centro de Investigación de Enfermedades Tropicales in Guerrero. Participating indigenous communities in Guerrero State approved the study in 2015. The results of the scoping review will contribute to the field of cultural safety and intercultural dialogue for the promotion of maternal health in indigenous communities.

\section{INTRODUCTION}

Maternal morbidity and mortality are inequitable burdens for many indigenous women
Strengths and limitations of this study

- Viewed from different standpoints, maternal health has multiple interpretations and multiple interacting factors that simple linear models cannot easily identify.

- Disentangling whether a study included traditional midwives or not will be challenging in times when retraining and professionalisation are becoming more prominent in Latin America.

- This scoping review uses fuzzy cognitive mapping to summarise results, generating soft models of causal relationships that require empirical testing.

- Heterogeneity of exposures and outcomes might require developing soft models generalised to a larger scale to allow for comparability.

- The review is part of a bigger initiative promoting intercultural dialogue between indigenous and Western perspectives, with a view to improving maternal health.

in the Americas. ${ }^{1-3}$ Living as they do at the very periphery of the Western health system, indigenous mothers often receive low-quality care from attenuated health services that lack human and financial resources. Colonial history in the Americas has weakened indigenous cultures, including their traditions to promote safe motherhood. ${ }^{4}$ Mutual mistrust between Western practitioners and traditional midwives creates additional distance and hampers collaboration. ${ }^{5}$ While their traditional and Western health providers largely ignore each other, indigenous mothers receive less appropriate Western services and they cannot rely solely on their weakened traditional resources.

Since 2004, no less than 18 literature reviews focussed on the effectiveness of retraining traditional midwives and redefining their traditional roles as auxiliary promoters of Western health services (table 1). A recurring problem is the reduction of traditional midwife 
Table 1 List of systematic reviews related to the field of traditional midwifery in relation to maternal health

\begin{tabular}{|c|c|c|}
\hline \# & Review & Approach \\
\hline \multirow[t]{3}{*}{1} & $\begin{array}{l}\text { Reference } \\
\text { Sibley and Sipe }{ }^{65} \text { (2004) }\end{array}$ & $\begin{array}{l}\text { Compares trained and } \\
\text { untrained TBAs. }\end{array}$ \\
\hline & $\begin{array}{l}\text { Time searched } \\
\text { up to } 1997 \text { (inferred, not stated) }\end{array}$ & \\
\hline & $\begin{array}{l}\text { Inclusion } \\
\text { Studies involving training of TBAs } \\
\text { (not stated). }\end{array}$ & \\
\hline \multirow[t]{3}{*}{2} & $\begin{array}{l}\text { Reference } \\
\text { Kruske and Barclay }^{7} \text { (2004) }\end{array}$ & $\begin{array}{l}\text { Documents studies that } \\
\text { address TBA training. }\end{array}$ \\
\hline & $\begin{array}{l}\text { Time } \\
1970 \text { to } 2003\end{array}$ & \\
\hline & $\begin{array}{l}\text { Inclusion } \\
\text { 'A review of the health and } \\
\text { sociological literature, and } \\
\text { international policy documents that } \\
\text { address TBA training'. }\end{array}$ & \\
\hline
\end{tabular}

\section{Reference}

Sibley et al ${ }^{66}(2004)$

Time

January 1970 to June 1999

Effectiveness of TBA training to improve access to skilled birth attendance for obstetric emergencies.

Inclusion

Published and unpublished studies: Treatment was TBA training; treatment group data were derived from TBAs or mothers and neonates whose care was provided by TBAs or who were living in areas where more than $50 \%$ of births were attended by TBAs.

4 Reference

Sibley et $a^{67}$ (2004)

Time

1970 to 2002

\section{Inclusion}

Published and unpublished studies on the relationship between TBA training and increased use of professional ANC.

\section{Reference}

Sibley et al ${ }^{68}(2007)$

Time

up to 2006

\section{Inclusion}

Published and unpublished randomised controlled trials, controlled before/after and interrupted time series studies comparing trained and untrained TBAs or women cared for/living in areas served by TBAs.

6 Reference

Lawn et a ${ }^{69-74}$ (2009)

Time

up to 2002 (updated in 2009)

Inclusion

Interventions and strategies that avert intrapartum-related adverse outcomes.
Effects of TBA training

on health behaviours and
Table 1 Continued

\begin{tabular}{|c|c|c|}
\hline \# & Review & Approach \\
\hline \multirow[t]{3}{*}{7} & $\begin{array}{l}\text { Reference } \\
\text { Kidney et al }{ }^{75} \text { (2009) }\end{array}$ & \multirow{3}{*}{$\begin{array}{l}\text { Effectiveness of community- } \\
\text { level interventions to reduce } \\
\text { maternal mortality. Some } \\
\text { interventions included } \\
\text { traditional midwives. }\end{array}$} \\
\hline & $\begin{array}{l}\text { Time } \\
\text { From inception to } 2006\end{array}$ & \\
\hline & $\begin{array}{l}\text { Inclusion } \\
\text { Maternity or childbearing-age } \\
\text { women, comparative study } \\
\text { designs with concurrent controls, } \\
\text { community-level interventions and } \\
\text { maternal death as an outcome. }\end{array}$ & \\
\hline \multirow[t]{2}{*}{8} & $\begin{array}{l}\text { Reference } \\
\text { Byrne and } \operatorname{Morgan}^{76}(2011)\end{array}$ & \multirow{2}{*}{$\begin{array}{l}\text { Increase of skilled birth } \\
\text { attendance after integration o } \\
\text { TBAs with the health system. }\end{array}$} \\
\hline & Time & \\
\hline
\end{tabular}

From inception to October 2010

Inclusion

Interventions of integration between TBA and formal health systems.

\section{Reference}

Wilson et al ${ }^{77}$ (2011)

Time

From inception to April 2011

Effectiveness of training and support of TBAs on the outcomes of perinatal, neonatal and maternal death.

\section{Inclusion}

Search terms were 'birth attend", 'traditional midwife', 'lay birth attendant', 'dais' and 'comadronas' in developing countries.

10 Reference

Glenton et al ${ }^{78}$ (2013)

Time

From inception to 2011

\section{Inclusion}

Studies that used qualitative methods for data collection and analysis and that focussed on the experiences and attitudes of stakeholders.

\section{Reference}

Vieira et al ${ }^{79}(2012)$

Time

From inception to June 2010 pregnancy outcomes.

(additional materials received until 2012).

\section{Inclusion}

TBAs had been attending births prior to the intervention; and a transition to skilled health personnel was in progress or planned.

12 Reference

Bohren et $a l^{80}$ (2014)

Time

From inception to April 2013

Explores factors affecting the implementation of LHW programmes for maternal and child health.

(In eight studies, LHWs were

TBAs who had received additional training.)

Inclusion

Study objectives related to barriers and/or facilitators to facility-based delivery and reporting qualitative data.

\section{Reference}

Lassi et a ${ }^{81}$ (2014)

Time

From inception to April 2013

Inclusion

Systematic reviews 


\section{Table 1 Continued}

\begin{tabular}{|c|c|c|}
\hline$\#$ & Review & Approach \\
\hline \multirow[t]{3}{*}{14} & $\begin{array}{l}\text { Reference } \\
\text { Mangham-Jefferies et al }{ }^{82} \text { (2014) }\end{array}$ & \multirow{3}{*}{$\begin{array}{l}\text { Assess cost-effectiveness } \\
\text { of strategies to improve } \\
\text { the demand and supply } \\
\text { of maternal and newborn } \\
\text { healthcare in low-income } \\
\text { and lower-middle-income } \\
\text { countries. }\end{array}$} \\
\hline & $\begin{array}{l}\text { Time } \\
\text { January } 1990 \text { to October } 2016\end{array}$ & \\
\hline & $\begin{array}{l}\text { Inclusion } \\
\text { Peer-reviewed and grey literature } \\
\text { reporting cost-effectiveness } \\
\text { measures based on primary data. }\end{array}$ & \\
\hline \multirow[t]{3}{*}{15} & $\begin{array}{l}\text { Reference } \\
\text { WHO recommendations on } \\
\text { health promotion interventions } \\
\text { for maternal and newborn health } \\
2015 . .^{8384}\end{array}$ & \multirow{3}{*}{$\begin{array}{l}\text { Effects of health interventions } \\
\text { during pregnancy, childbirth } \\
\text { and the postnatal period. } \\
\text { Effects of health behaviours of } \\
\text { women during these periods } \\
\text { to care for themselves and } \\
\text { their babies. } \\
\text { (Interventions involving TBAs } \\
\text { included training, promotion } \\
\text { of skilled attendance and } \\
\text { promotion of partnership and } \\
\text { linkage.) }\end{array}$} \\
\hline & $\begin{array}{l}\text { Time } \\
\text { up to } 2015 \text { (not indicated) }\end{array}$ & \\
\hline & $\begin{array}{l}\text { Inclusion } \\
\text { Not explained. }\end{array}$ & \\
\hline \multirow[t]{3}{*}{16} & $\begin{array}{l}\text { Reference } \\
\text { Lassi et al/ }{ }^{85} \text { (2016) }\end{array}$ & \multirow{3}{*}{$\begin{array}{l}\text { Impact of different strategies } \\
\text { to improve maternal and } \\
\text { neonatal healthcare-seeking. } \\
\text { (Interventions involving TBAs } \\
\text { focussed on training.) }\end{array}$} \\
\hline & $\begin{array}{l}\text { Time } \\
\text { From inception to January } 2015\end{array}$ & \\
\hline & $\begin{array}{l}\text { Inclusion } \\
\text { All experimental studies from LMICs } \\
\text { that assessed the healthcare- } \\
\text { seeking behaviour or pattern for } \\
\text { maternal and newborn healthcare } \\
\text { and illnesses. }\end{array}$ & \\
\hline \multirow[t]{3}{*}{17} & $\begin{array}{l}\text { Reference } \\
\text { Miller and Smith }{ }^{86}(2017)\end{array}$ & \multirow{3}{*}{$\begin{array}{l}\text { Effectiveness of interventions } \\
\text { to find new roles for TBAs on } \\
\text { maternal and newborn health } \\
\text { outcomes. }\end{array}$} \\
\hline & $\begin{array}{l}\text { Time } \\
2000 \text { to } 2012 \text { (updated 2015? not } \\
\text { indicated) }\end{array}$ & \\
\hline & $\begin{array}{l}\text { Inclusion } \\
\text { Secondary analysis of studies } \\
\text { identified in previous reviews } \\
\text { and a mapping of maternal health } \\
\text { literature. }{ }^{87}\end{array}$ & \\
\hline \multirow[t]{3}{*}{18} & $\begin{array}{l}\text { Reference } \\
\text { Blanchard et }\left.a\right|^{31} \text { (2019) }\end{array}$ & \multirow{3}{*}{$\begin{array}{l}\text { CHW include trained lay } \\
\text { workers, health volunteers, } \\
\text { community health agents, } \\
\text { TBAs and community } \\
\text { midwives. }\end{array}$} \\
\hline & $\begin{array}{l}\text { Time } \\
\text { Studies conducted after } 1990 \text { and } \\
\text { published between January } 1996 \\
\text { and August } 2017 \text {. }\end{array}$ & \\
\hline & $\begin{array}{l}\text { Inclusion } \\
\text { Studies examining the effects of } \\
\mathrm{CHW} \text { interventions in LMIC on } \\
\text { maternal and newborn health } \\
\text { outcomes across socioeconomic } \\
\text { groups. }\end{array}$ & \\
\hline
\end{tabular}

ANC, antenatal care ; CHW, community health workers; LHW, lay health workers; LMIC, low-income and middle-income countries; TBA, traditional birth attendants.

with traditional birth attendant (TBA), a term that refers to unskilled personnel providing limited support during the childbirth event. ${ }^{6}$ Several interventions explored training birth attendants in Western birthing skills.

In indigenous communities with traditional health systems, with particularities across different cultural groups, traditional midwives accompany women from childhood and through motherhood; their role is much wider (including family and other social relations) and deeper (including counselling and emotional support from menarche to menopause) than can be summarised as 'birth attendance'. ${ }^{8}$ Traditional midwives usually have their own hierarchy, defined by capacity to deal with complex health problems. ${ }^{9}$ There is little research on interventions that support traditional midwives and recognises their knowledge, and even less research on adjusting the Western health system to work with traditional midwives. ${ }^{7}$

Maternal health is a capacious concept that incorporates complex sociocultural mechanisms affecting the well-being of women, their offspring and communities. ${ }^{10}$ Existing literature reviews (table 1) focus on biomedical outcomes like maternal morbidity and mortality, neonatal survival or uptake of Western health services. A scoping review allows us to address broader questions, including what the outcomes are. ${ }^{11}$ The approach allows incorporation of intersectional factors in a general landscape that can improve understanding of the full role of traditional midwifery. This is central to services that are respectful of indigenous cultures where women still use this resource, improving interactions between indigenous and Western health services. ${ }^{12}$ More culturally safe health services increase patient perceptions of physical, spiritual, social and emotional safety. ${ }^{13}$ Another benefit of a mutually respectful environment is the concerting of traditional and Western services together to improve maternal health. ${ }^{14}$

Part of a larger initiative project to understand the role that traditional midwifery has in safe birth in cultural safety, this scoping review aims to contribute to intercultural dialogue between traditional and Western health systems. ${ }^{15}$ Our objective is to collate and assess evidencethat identifies factors, including the role and influence of traditionalmidwives, that affect maternal health in indigenous communities in theAmericas. The larger project will develop a composite theory of change from three knowledge bases: (1) the scoping review described in this protocol; (2) the research team's understanding of the intercultural dialogue dynamics as these relate to safe birth; and (3) traditional midwives' understanding of safe birth. Representing each knowledge set as a fuzzy cognitive map, we will adapt the Weight of Evidence ${ }^{16}$ approach to combine the three sources into one model to inform decision making and a stakeholder-led analysis of a cluster randomised controlled trial. ${ }^{15}$ In this protocol, we focus on the procedures to conduct the scoping review and mention the additional use of the review results. A full description of the procedure to combine the three knowledge sources is the subject of an additional report.

\section{METHODS}

This protocol follows the PRISMA-P (Preferred Reporting Items for Systematic Reviews and Meta-Analyses Protocols) guidelines and the Joanna Briggs Institute Reviewer's 
Manual to assure transparency, accuracy and completeness. ${ }^{17} 18$ It follows Arksey and O'Malley's methodological framework consisting of six stages. ${ }^{19}$ All members of the research team developed, reviewed and agreed with the protocol.

\section{Stage 1: identify the research question}

A convergent mixed studies review ${ }^{2021}$ will address the question: What factors, including the role and influence of traditional midwives, promote or reduce maternal health in indigenous settings in the Americas and, based on available qualitative and quantitative evidence, what is the relative weight of their influence?

Secondary questions of the included studies are:

- What are the indicators of maternal health?

- How are the concepts of cultural safety and intercultural dialogue considered?

- What is the influence of traditional midwifery on maternal health?

- What is the effect on maternal health of interventions supporting traditional midwives?

\section{Stage 2: identifying relevant studies}

A health librarian (MM) developed the comprehensive search strategy to explore the following databases: CINAHL Nursing Journal Databases, Scopus, Latin American and Caribbean Health Sciences Literature (LILACS), MEDLINE/PubMed, Embase and Google Scholar. The review will include studies in human populations reported in English, Spanish, French or Portuguese published at any time up to the date of the search.

The strategy applies a targeted, iterative searching technique that documents new keywords emerged from screened articles. ${ }^{22}$ This strategy consists of two steps: (1) an initial search in MEDLINE/PubMed to analyse the text words in the titles and abstracts retrieved, and the index terms used to describe the article; and (2) using the updated terms, conduct a second search and translate the search to run across the other databases and grey literature. The final report of the review will document in detail these two steps. Online supplementary file 1 presents a draft literature search strategy for step 1.

Using the Google (Google LLC) search engine, we will identify unpublished studies and grey literature, such as institutional and advocacy reports. In the advanced search section, we will use consistent search terms identified during the screening stage of published literature. To increase precision, each search will use the Google versions for the country of interest and limit the results for that country. We will use the computer of the leading author to guarantee that the personal filters of Google are in favour of academic information about traditional midwives. The screening process will be limited to the first 100 results returned for reasons of feasibility. We will use the title and short text underneath for initial screening. ${ }^{23}$ To facilitate the transparency of web searching, for each website, we will report the URL, dates searched, search terms and the citation details of any included literature.
To document specific searches of government information and reports that are not published commercially, we will complete hand searches of the websites following the procedure of the Canadian Agency for Drugs and Technologies for Health checklist. ${ }^{24}$

We will search the reference list of included references for additional studies, but we do not propose to contact authors for further information.

\section{Stage 3: study selection}

After completing the search and excluding duplicated records using EndNote (X9.3.1, Clarivate Analytics), we will digitise the list of references in Rayyan (Qatar Computing Research Institute) $)^{25}$ to support the selection process, and two independent researchers will select the studies. The independent researchers will reconcile the differences, and if they do not reach consensus, a third party will decide the inclusion or exclusion. The first selection round will use title and abstract as criteria, and a second round will use full content to support the decision.

In scoping reviews, the selection process can be iterative. When the research team engages in study selection and more deeply explore the literature, they may get new information to enhance the identification phase. ${ }^{22}$ We will document any adjustment to the search strategy occurring after the selection process has already started. Included studies will satisfy the following four criteria:

\section{The study addresses maternal health issues in indigenous} populations

The concept of maternal health is a broad term without a common definition and standard identification criteria. Part of the challenge is the extended debate on defining health, which is even deeper across different cultural backgrounds. ${ }^{8}$ For example, traditional midwives in Guerrero, Mexico, included in their definition of a healthy mother, those with a healthy baby and a healthy husband. The WHO focusses the definition on the mother and uses a time period to circumscribe the concept as 'the health of women during pregnancy, childbirth and the postpartum period'. ${ }^{26}$ In the negative interpretation of the concept of maternal health, maternal mortality has usually been used as a critical measure. But it only represents a small fraction of the problem when compared with the occurrence of maternal morbidity, understood as 'any health condition attributed to and/or aggravated by pregnancy and childbirth that has a negative impact on the woman's well-being, ${ }^{27}$

According to Graham, maternal health is commonly conceptualised as a discrete state of negative outcomes in terms of morbidity and mortality, characterised by physical rather than social or mental manifestations, and by a narrow time perspective. ${ }^{28}$ Especially in the context of indigenous communities, spiritual and environmental domains can have strong relevance. Graham suggested the need for flexible interpretations to recognise that 'maternal health encompasses positive or negative 
outcomes-physical, social or mental, in a woman from any cause related to childbearing or its management'. ${ }^{28}$

Our review will therefore include studies that report on maternal health irrespective of the definition of this concept. The review will include studies on positive or negative outcomes from any cause related to childbearing or its management.

The study reports on the role or influence of traditional midwives Birth traditions in most indigenous cultures involve someone attending women throughout pregnancy and delivery, many of them including support from menarche to menopause. ${ }^{10}$ To clarify terminology, we distinguish between three categories of birth attendants in indigenous contexts: (1) casual or coincidental birth helpers, who might help in a family or neighbourhood emergency; (2) trained birth attendants (different to TBAs, but conflated by the acronym TBA), are individuals who receive training in Western birth practices and who might have received an official certification; and (3) authentic traditional midwives, whose recognition by their communities is reflected in the number of births they attend each year, the outcomes for their patients and the traditional knowledge they hold. Traditional midwives "provide basic healthcare and advice before, during and after pregnancy and childbirth (...) based primarily on experience and knowledge acquired informally through the traditions and practices of the communities where they originated' ${ }^{29}$ With significant cultural particularities in their knowledge, training and practice between and within indigenous groups, traditional midwives have their own hierarchy defined by their capacity to deal with complex health problems. ${ }^{9}$

We will only include studies of authentic traditional midwives. However, this concept receives multiple interpretations in the literature, which are reflected in the use of apparently equivalent terms such as community midwives, lay midwives or TBAs. ${ }^{30}$ These terms are often conflated under the broader concept of community health worker, ${ }^{31}{ }^{32}$ which, although it recognises the community roots of traditional midwives, neglects the culture specific roots of their practice. In a similar way, the appellation of lay midwives is used to suggest lack of professional qualification or expert knowledge. Extensive use of the term $\mathrm{TBA}^{33} 34$ in the literature suggests limiting the role of traditional midwives to the actual delivery, ignoring their experience, cultural relevance and social role, and that they usually accompany women throughout pregnancy and even from the menarche. ${ }^{635}$

Contemporary distortions or misunderstandings of traditional health practitioner roles have reinforced mistrust in official health personnel. This has not been helped by charlatans and health entrepreneurs who mimic the traditional healer role on a fee-for-service basis, but who lack the training and spiritual foundations to play this role. ${ }^{32}$ An additional layer of complexity is that mainstream Western medicine often bundles indigenous health systems, anchored in specific cultures and history, with alternative or complementary therapies, ${ }^{36}$ which are abstracted from cultural identities and might not have proven effectiveness or safety. ${ }^{37}$ We will accept reports of traditional midwifery assuming authenticity, but the hierarchy and genuineness of participants will be discussed in the final report.

The review will distinguish traditional midwives from professional midwives. The main difference between these categories is the origin of their knowledge and practice. The appellative of traditional recognises the link with traditional knowledge and worldviews of indigenous cultures, whereas professional situates midwives in an institutional context of Western biomedicine and international standards. ${ }^{38}$ Professionalisation of midwifery started in Europe after the replacement of traditional midwives $^{3940}$ and has expanded since the $19^{\text {th }}$ century mainly through colonial education. ${ }^{41}$ Professional midwives receive formal education to perform their role, either through direct entry or after basic nursing, with diverse cadres and appellations. ${ }^{42}$ Their practice has a wide scope that includes primary care of woman and newborns, less biomedical interventions and more humanised interaction with patients. ${ }^{38} 43$ An essential difference between traditional and professional midwives is that the latter enjoy official accreditation and licensing according to global guidelines. A practical consequence is higher esteem for professional midwives in biomedical contexts. ${ }^{44}$ Promoters of this category of health worker often equate it with the concept of skilled attendant, assuming that compliance with international regulations and standards assures a higher level of competency and quality of care. ${ }^{45}$

Yet there is no unanimously accepted international definition of what constitutes 'skilled'. Among professional (licensed) midwives, for example, there is a discussion on whether practitioners should conform to a restrictive Western definition or celebrate the diversity of cultural perspectives. ${ }^{46}{ }^{47}$ It is becoming increasingly common for licensed midwives to adopt and apply indigenous techniques learnt from traditional midwives. ${ }^{48}$ And at the same time, more indigenous people and even traditional midwives are receiving formal training, accreditation and permission to practice. ${ }^{49}$ This landscape becomes even more complex if we consider emerging roles such as doulas, who provide continuous, one-on-one emotional and informational support during the perinatal period but do not provide medical services. ${ }^{50} 51$ Non-indigenous doulas sometimes apply practices learnt from indigenous traditions, and indigenous doulas usually accompany other indigenous mother in navigating Western services in countries where traditional midwifery is forbidden. ${ }^{52}$

To address the multiple interpretations expressed in terminology referring to traditional midwives, we will consider the study as including authentic traditional midwives if the report explicitly uses this term or TBAs, or if it describes the link of their practice to the traditional culture of the community and refers to a traditional locally recognised role helping women during pregnancy, delivery or postpartum, even if the traditional midwives have received some 
informal training. The review will exclude studies reporting on professional midwives even if they come from an indigenous community. Online supplementary file 2 presents a list of terms that could be referring to traditional midwives. To allow for a comprehensive search, we will not restrict the search strategy using these terms, but the list will guide the screening process.

\section{It is an empirical study}

The review will include qualitative, quantitative or mixedmethods studies, observational or experimental, that address maternal health outcomes. We will not include ethnographic descriptions of traditional midwifery that do not report on its effects on maternal health outcomes.

\section{The study setting is in the Americas}

Given the variability in traditions and cultural practices, we will restrict the review to studies in indigenous communities in the Americas.

\section{Exclusion criteria}

The review will exclude theoretical models without empirical support. The final report will contain a list of the studies excluded and the reasons for doing so. We will document the process in a diagram according to the PRISMA guidelines. ${ }^{53}$

\section{Quality appraisal}

Although some scoping reviews do not conduct quality appraisal, ${ }^{22}$ we consider it is necessary in this study to determine the strength of the current evidence. Quality assessment of the included studies will follow the MMAT, ${ }^{54}$ the results from the quality assessment will contribute to interpret the weights in the fuzzy cognitive maps described in Stage 5.

\section{Stage 4: charting the data}

Based on the reading of full texts, two independent authors will extract concepts related to safe birth using an electronic form with the following items:

a. Study (title, year of the study, publication type (published/unpublished), year of publication, country, type of study (qualitative/ quantitative/mixed), study design and population).

b. Study citation details.

c. Quality according to the MMAT.

d. Maternal health outcomes reported in the study.

e. Characteristics of traditional midwives involved in the study.

f. Approach of the study to cultural diferences.

g. Factors related to maternal health studied and reported (complete $\mathrm{h}$ to $\mathrm{j}$ for all relationships).

$\mathrm{h}$. If quantitative: what is the measure? And what is the value of the relationship with maternal health? (Include confidence intervals - CIs.)

i. If qualitative: what is the argument or insight about the importance of this relationship with safe birth (copy and paste)? j. Does the study report other relations among factors? If yes, identify all the relationships and complete $h$ or i for all of them.

To ensure consistency and to test the data abstraction format, a data abstraction pilot will include five randomly selected articles. The pilot will identify necessary changes prior to abstracting the remaining articles. The data extractors will compare results and a third party will resolve irreconcilable discrepancies.

\section{Stage 5: collating, summarising and reporting the results}

The reporting will follow the PRISMA Scoping Reviews (PRISMA-ScR) guidelines. $^{53}$ Reporting will produce tables and charts of the geographic and population distribution of studies; the factors included in the review; the cultural approach to traditional midwifery of each study; the research methods adopted; and the measures of maternal health used. The report will present an illustrative fuzzy cognitive map, as a logic framework for convergent synthesis ${ }^{21}$ of the literature and the interpretation of its weights in terms of the influence that each factor might have on maternal health according to the model.

\section{Fuzzy cognitive mapping}

The pivotal tool for summarising the results of this review is fuzzy cognitive mapping (FCM). This is a graphic representation of soft models composed of elements or concepts and relations between elements. Each element is a node (factors identified in point $\mathrm{g}$ of the data extraction form), and each relationship is represented as an edge (arrow) linking nodes together. These graphics represent assumptions on causal relations and can be based on data or unwritten knowledge. ${ }^{55}$ The edges represent causal relations, so the direction of the arrows matters. ${ }^{56}$ The relations or edges can be assigned different values to quantify their strength in a relative way (hence the term fuzzy). As the causal knowledge is often uncertain, or at least different from the viewpoints of different stakeholders (for each of whom it might feel certain), fuzzy models allow us to understand 'hazy degrees of causality between hazy causal concepts' using fuzzy causal algebra. ${ }^{57}$ Figure 1 illustrates a fuzzy cognitive map from traditional midwives in Guerrero state, describing their views about protective factors for maternal health. ${ }^{58}$

An edge list is a tabular format to represent the relationships in a fuzzy cognitive map. An edge list consists of a table with two initial columns, the first to indicate the origin factor (from) and the second to indicate the consequence factor (to). Additional columns will indicate the supporting evidence of the relationship (items $\mathrm{h}$ or $\mathrm{i}$ of the data extraction form) and the corresponding reference. Each relationship corresponds to a row.

Based on extracted data, we will plot a fuzzy cognitive map using yEd graphical tools, scaling the effect measures into a range ( -1 to 1$)$ assigning negative and positive signs for inhibitory and excitatory relationships, respectively. Adapting the Weight of Evidence approach proposed by Dion et $a l l^{59}$ it is possible to calculate common effect estimates 


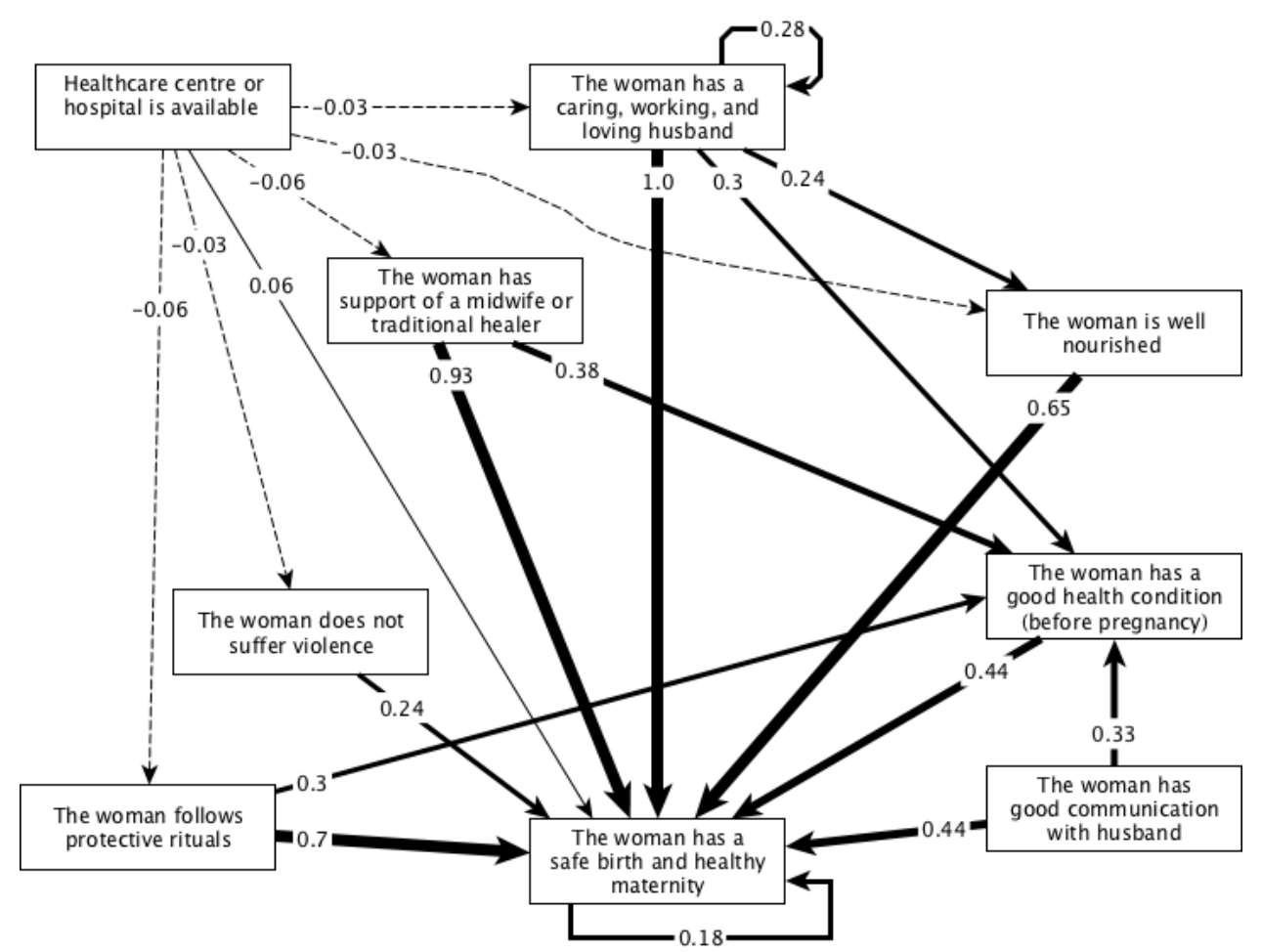

Figure 1 Fuzzy cognitive map of protective factors for maternal health from Me'Phaa and Nancue ñomda traditional midwives in Guerrero. Solid arrows represent excitatory relationships and dashed arrows represent inhibitory relationships. The thickness of the arrows varies according to the weight of the relationships. The numbers on the arrows represent the weight of the influence of one factor on another, with 1 being the highest influence.

to summarise quantitative data on the influence between factors. Wherever ORs are available, the formula proposed by Šajna will transform the values into a measure of the weight $(w)$ in the symmetric range (-1 to 1$)$ :

When multiple effect estimates describe the same relationship between factors, we will calculate a summary measure using standard approaches to meta-analysis. If the studies provide statistics other than ORs, such as ${ }^{2}$ or mean differences, we will convert them to the standardised mean difference $(d)$ and then convert $d$ to an OR using the following formula. ${ }^{60}$

$$
O R=\exp \left(\frac{\mathbb{I l} d}{\sqrt{3}}\right)
$$

Where $\varpi$ is the mathematical constant (approximately 3.14159).

For qualitative relationships, based on their reading of the context and report, two independent researchers will propose a value in the range $(-1$ to 1$)$ to indicate their interpretation of the weight and direction of the influence of each factor. They will propose these weights for qualitative relationships, considering all the qualitative and quantitative relationships in the map. They will reconcile differences by consensus (both agreeing on a new value after discussion), resolving discrepancies with the intervention of a third reviewer. To facilitate weighting using and ordered scale between 1 and $5,{ }^{61}$ researchers will answer two if-then questions for each relationship. ${ }^{62}$ First, if (the origin factor) increases, then (the resulting factor) would increase or decrease? Weights will be positive for the former and negative for the latter. Second, if (the origin factor) increases, then (the resulting factor) would rarely change or very often change? In a scale between one if the resulting factor rarely changes and five if it changes very often. Researchers will review all the weights that they assigned in a second round to guarantee that the weights are comparable across all the relationships in the map. We will contrast the results of the classification with a technique for operator-independent weighting based on Harris's method for discourse analysis ${ }^{63}$ that assigns the weight of the relationship based on the number of times a relationship was identified. We do not use it as the primary method because it is still under development.

In the final map, with all relationships identified in the scoping review, the transitive closure algorithm will calculate the weights of the relationships considering the entire system. $^{13}$ This procedure is available in CIETmap, an open-source Windows-like interface with the $\mathrm{R}$ programming language. ${ }^{64}$

\section{Stage 6: consultation exercise}

Arksey and O'Malley recognise the benefit of discussing the final results of a scoping review with experts. ${ }^{19}$ The Weight of Evidence ${ }^{16}$ approach goes further, recognising that the literature review presents a valuable side of the story to be contrasted and expanded with the views and experiences of those affected by the issue. We will use this to generate a composite model incorporating two additional sources, the knowledge of traditional midwives in 
Guerrero and the views of the research team involved in a cluster-randomised controlled trial supporting traditional midwifery. ${ }^{15}$ This will be completed and reported separately.

\section{Patient and public involvement}

This research involves no direct patient or public involvement, but the design of the study is the result of participatory research involving traditional midwives from Guerrero State, Mexico.

\section{CONCLUSION}

This protocol describes a scoping review to map factors, including the roles of traditional midwives who can contribute to or detract from maternal health in indigenous communities. The review will contribute to the understanding of maternal health in a complex interaction of variables where indigenous cultures meet Western medicine. It reflects a shift in approach to traditional midwifery, recognising its influence on health outcomes cannot be understood in isolation. FCM offers a systematic and visual way to deal with heterogeneity and uncertainty of epidemiological data, as well as a common language to juxtapose Western knowledge with other sources of knowledge such as indigenous wisdom and experience.

Fuzzy cognitive maps are conceptual models depicting causal assumptions and prior beliefs. The maps expand the realm of possible improvement strategies by identifying factors from multiple knowledge bases and, in each knowledge base reflect direct or indirect interactions. The influences between factors, however, do not translate as probabilities as they might from some meta-analyses. The map generated by the scoping review will inform a participatory process to update currently available knowledge with additional evidence from the experience of traditional midwives and experimental data.

Acknowledgements Participatory Research at McGill, particularly Anna Dion, contributed valuable insights on the use of fuzzy cognitive mapping. Genevieve Gore offered initial ideas to adjust the search strategy. German Zuluaga and Anne Marie Chomat read and commented on the initial version of this protocol.

Collaborators Anna Dion, Participatory Research at McGill Univeristy's Department of Family Medicine.

Contributors IS is the guarantor. IS, NA, and AC drafted the manuscript. All authors contributed to the development of the selection criteria, the risk of bias assessment strategy and data extraction criteria. MM developed the search strategy and the compliance with quality standards for scoping reviews. NA provided statistical expertise as a coauthor of the Weight of Evidence. AC adjusted the manuscript for dissemination. SP is the sponsor of the work with traditional midwives in Guerrero. JP contributed to define procedures for data collection. All authors read, provided feedback and approved the final manuscript.

Funding This scoping review is funded by CIETCanada and the Center of Intercultural Medical Studies in Colombia. IS and JP are scholars of the Fonds de la Recherche en Sante du Quebec and CeiBA Foundation. The Centro de Investigación de Enfermedades Tropicales at the Universidad Autónoma de Guerrero is the sponsor of the study.

Competing interests None declared.

Patient consent for publication Not required.

Provenance and peer review Not commissioned; externally peer-reviewed.
Supplemental material This content has been supplied by the author(s). It has not been vetted by BMJ Publishing Group Limited (BMJ) and may not have been peer-reviewed. Any opinions or recommendations discussed are solely those of the author(s) and are not endorsed by BMJ. BMJ disclaims all liability and responsibility arising from any reliance placed on the content. Where the content includes any translated material, BMJ does not warrant the accuracy and reliability of the translations (including but not limited to local regulations, clinical guidelines, terminology, drug names and drug dosages), and is not responsible for any error and/or omissions arising from translation and adaptation or otherwise.

Open access This is an open access article distributed in accordance with the Creative Commons Attribution Non Commercial (CC BY-NC 4.0) license, which permits others to distribute, remix, adapt, build upon this work non-commercially, and license their derivative works on different terms, provided the original work is properly cited, appropriate credit is given, any changes made indicated, and the use is non-commercial. See: http://creativecommons.org/licenses/by-nc/4.0/.

\section{ORCID iDs}

Iván Sarmiento http://orcid.org/0000-0003-2871-1464

Sergio Paredes-Solís http://orcid.org/0000-0002-3015-3038

\section{REFERENCES}

1 Department of Economic and Social Affairs. Division for social policy and development secretariat. Secretariat of the permanent forum on indigenous issues. State of the world's indigenous peoples. New York: United Nations, 2009.

2 Armenta-Paulino N, Sandín-Vázquez M, Bolúmar F. Indigenous language and inequitable maternal health care, Guatemala, Mexico, Peru and the Plurinational state of Bolivia. Bull World Health Organ 2019;97:59-67.

3 Lalonde AB, Butt C, Bucio A. Maternal health in Canadian Aboriginal communities: challenges and opportunities. J Obstet Gynaecol Can 2009;31:956-62.

4 King M, Smith A, Gracey M. Indigenous health part 2: the underlying causes of the health gap. Lancet 2009;374:76-85.

5 Ohaja M, Murphy-Lawless J. Unilateral collaboration: the practices and understandings of traditional birth attendants in southeastern Nigeria. Women Birth 2017;30:e165-71.

6 Pigg SL. Acronyms and effacement: traditional medical practitioners (TMP) in international health development. Soc Sci Med 1995;41:47-68

7 Kruske S, Barclay L. Effect of shifting policies on traditional birth attendant training. J Midwifery Womens Health 2004;49:306-11.

8 Jordan B. Birth in four cultures: a crosscultural investigation of childbirth in Yucatan, Holland, Sweden, and the United States. 4th edn. Long Grove, IL: Waveland Press, 1993.

9 Sesia P. 'Women come here on their own when they need to' Prenatal care, authoritative knowledge and maternal health in Oaxaca. In: Davis-Floyd R, Sargent C, eds. Childbirth and authoritative knowledge: cross-cultural perspectives. Berkeley: University of California Press, 1997: 397-420.

10 Kennedy HP, Cheyney M, Dahlen HG, et al. Asking different questions: a call to action for research to improve the quality of care for every woman, every child. Birth 2018;45:222-31.

11 Colquhoun HL, Levac D, O'Brien KK, et al. Scoping reviews: time for clarity in definition, methods, and reporting. $J$ Clin Epidemiol 2014;67:1291-4.

12 Cameron M, Andersson N, McDowell I, et al. Culturally safe epidemiology: oxymoron or scientific imperative. Pimatisiwin $J$ Aborig Indig Community Heal 2010;8:89-116.

13 Kruske S, Kildea S, Barclay L. Cultural safety and maternity care for Aboriginal and Torres Strait Islander Australians. Women Birth 2006;19:73-7.

14 United Nations Educational Cultural and Scientific Organization. Investing in cultural diversity and intercultural dialogue. Paris, France, 2009. Available: https://unesdoc.unesco.org/ark:/48223/ pf0000184755 [Accessed 30 Apr 2014].

15 Sarmiento I, Paredes-Solís S, Andersson N, et al. Safe birth and cultural safety in southern Mexico: study protocol for a randomised controlled trial. Trials 2018;19:354.

16 Dion A, Joseph L, Jimenez V, et al. Grounding evidence in experience to support people-centered health services. Int J Public Health 2019;64:797-802.

17 Shamseer L, Moher D, Clarke M, et al. Preferred reporting items for systematic review and meta-analysis protocols (PRISMA-P) 2015: elaboration and explanation. BMJ 2015;350:g7647. 
18 Peters M, Godfrey C, Mclnerney P, et al. Scoping reviews. In: Aromataris E, Munn Z, eds. Joanna Briggs institute reviewer's manual. The Joanna Briggs Institute, 2017. https://reviewersmanual. joannabriggs.org/

19 Arksey H, O'Malley L. Scoping studies: towards a methodological framework. Int J Soc Res Methodol 2005;8:19-32.

20 Pluye P, Hong QN. Combining the power of stories and the power of numbers: mixed methods research and mixed studies reviews. Annu Rev Public Health 2014;35:29-45.

21 Harden A, Thomas J, Cargo M, et al. Cochrane qualitative and implementation methods group guidance series-paper 5 : methods for integrating qualitative and implementation evidence within intervention effectiveness reviews. J Clin Epidemiol 2018;97:70-8.

22 Morris M, Boruff JT, Gore GC. Scoping reviews: establishing the role of the librarian. J Med Libr Assoc 2016;104:346-54.

23 Godin K, Stapleton J, Kirkpatrick SI, et al. Applying systematic review search methods to the grey literature: a case study examining guidelines for school-based breakfast programs in Canada. Syst Rev 2015;4:138.

24 CADTH. Grey matters: a practical tool for searching health-related grey literature, 2018. Available: https://www.cadth.ca/resources/ findings-evidence [Accessed 7 May 2020].

25 Ouzzani M, Hammady H, Fedorowicz Z, et al. Rayyan-a web and mobile APP for systematic reviews. Syst Rev 2016;5:1-10.

26 World Health Organization. WHO-Europe maternal and newborn health., 2019. Available: http://www.euro.who.int/en/health-topics/ Life-stages/maternal-and-newborn-health/maternal-and-newbornhealth\# [Accessed 18 Dec 2019].

27 Firoz T, Chou D, von Dadelszen P, et al. Measuring maternal health: focus on maternal morbidity. Bull World Health Organ 2013;91:794-6.

28 Graham WJ, Campbell OM. Maternal health and the measurement trap. Soc Sci Med 1992;35:967-77.

29 International Labour Office. International standard classification of occupations 2008 (ISCO-08) : structure, group definitions and correspondence tables. Geneve, Switzerland: International Labour Office, 2012. http://ebookcentral.proquest.com/lib/mcgill/detail. action?doclD=991922

30 Schwartz DA. A glossary for anthropological research referring to indigenous peoples of Mexico and Central America BT - maternal death and pregnancy-related morbidity among indigenous women of Mexico and Central America: an anthropological, epidemiological, and biome. Cham: Springer International Publishing, 2018: 743-74.

31 Blanchard AK, Prost A, Houweling TAJ. Effects of community health worker interventions on socioeconomic inequities in maternal and newborn health in low-income and middle-income countries: a mixed-methods systematic review. BMJ Glob Health 2019;4:e001308

32 World Health Organization. District health systems unit. traditional healers as community health workers, 1991. Available: http://apps. who.int/iris/handle/10665/60375 [Accessed 16 Aug 2017]

33 Leedam E. Traditional birth attendants. Int J Gynaecol Obstet 1985;23:249-74.

34 World Health Organization, The United Nations Children's Emergency Fund, United Nations Population Fund. Traditional birth attendants: a joint WHO/UNFPA/UNICEF statement. Geneva, 1992. Available: http://www.who.int/iris/handle/10665/38994 [Accessed 19 Jan 2019].

35 Hinojosa SZ. Authorizing tradition: vectors of contention in highland Maya midwifery. Soc Sci Med 2004;59:637-51.

36 World Health Organization. WHO traditional medicine strategy 20142023. Geneva, Switzerland, 2013. Available: http://apps.who.int/iris/ handle/10665/92455 [Accessed 8 Apr 2014].

37 National Agency for Drug and Food Control, World Health Organization. Trips, $C B D$ and traditional medicines: concepts and questions. Report of an ASEAN workshop on the TRIPS agreement and traditional medicine. Jakarta, Indonesia, 2001.

38 Jefford E, Alonso C, Stevens JR. Call us midwives: critical comparison of what is a midwife and what is midwifery. Int $J$ Childbirth 2019;9:39-50.

39 Högberg U. The decline in maternal mortality in Sweden: the role of community midwifery. Am J Public Health 2004;94:1312.

40 De Brouwere V, Tonglet R, Van Lerberghe W. Strategies for reducing maternal mortality in developing countries: what can we learn from the history of the industrialized West? Trop Med Int Health 1998;3:771-82.

41 United Nations Population Fund. The State of the World's Midwifery 2011. New York, 2011. Available: https://www.unfpa.org/ publications/state-worlds-midwifery-2011 [Accessed 22 Apr 2020].

42 United Nations Population Fund, International Confederation of Midwives, World Health Organization. The state of the world's midwifery 2014: a universal pathway. a woman's right to health. New
York, 2014. Available: http://www.unfpa.org/sowmy [Accessed 16 Feb 2017].

43 Kennedy HP, Shannon MT, Chuahorm U, et al. The landscape of caring for women: a narrative study of midwifery practice. $J$ Midwifery Womens Health 2004;49:14-23.

44 World Health Organization. Department of reproductive health and research. making pregnancy safer: the critical role of the skilled attendant. A joint statement by WHO, ICM and FIGO. Geneva, 2004. Available: http://whqlibdoc.who.int/publications/2004/9241591692. pdf [Accessed 8 Nov 2018]

45 World Health Organization. Defining competent maternal and newborn health professionals. Geneva, 2018. Available: http://apps. who.int/iris/handle/10665/272817 [Accessed 19 Jan 2019].

46 Tritten J. International midwife: global alliance of midwives. Midwifery Today 1999;46.

47 Fullerton JT, Thompson JB. International confederation of midwives core documents: their added value for us midwifery associations. $J$ Midwifery Womens Health 2013;58:130-2.

48 Foster J, Alonso C. Contemporary issues in the training, practice, and implementation of midwifery for indigenous women in Mexico BT. In: Schwartz DA, ed. Maternal death and pregnancy-related morbidity among indigenous women of Mexico and Central America: an anthropological, epidemiological, and biomedical approach. Cham: Springer International Publishing, 2018: 313-26.

49 Braine T. Mexico's midwives enter the mainstream. Bull World Health Organ 2008;86:244-5

50 Kozhimannil KB, Attanasio LB, Jou J, et al. Potential benefits of increased access to doula support during childbirth. Am J Manag Care 2014;20:e340-52.

51 Bohren MA, Hofmeyr GJ, Sakala C, et al. Continuous support for women during childbirth. Cochrane Database Syst Rev 2017;7:CD003766.

52 Ireland S, Montgomery-Andersen R, Geraghty S. Indigenous Doulas: a literature review exploring their role and practice in Western maternity care. Midwifery 2019;75:52-8.

53 Tricco AC, Lillie E, Zarin W, et al. PRISMA extension for scoping reviews (PRISMA-ScR): checklist and explanation. Ann Intern Med 2018;169:467.

54 Hong QN, Gonzalez-Reyes A, Pluye P. Improving the usefulness of a tool for appraising the quality of qualitative, quantitative and mixed methods studies, the mixed methods appraisal tool (MMAT). J Eval Clin Pract 2018;24:459-67.

55 Gray S, Zanre E, Gray SRJ. Fuzzy cognitive maps as representations of mental models and group beliefs. In: Papageorgiou El, ed. Fuzzy cognitive maps for applied sciences and engineering. Berlin: Springer, 2014: 29-48.

56 Glymour M, Greenland S. Causal Diagrams. In: Rothman K, Greenland S, Lash T, eds. Modern epidemiology. Philadelphia: Wolters Kluwer Health/Lippincott Williams \& Wilkins, 2008: 183-211.

57 Kosko B. Fuzzy cognitive maps. Int J Man Mach Stud 1986;24:65-75.

58 Sarmiento I, Paredes-Solís I, Loutfi I, Dion I, Cockcroft I, Andersson I, , , , , , , , ,. Fuzzy cognitive mapping and soft models of Indigenous knowledge on maternal health in Guerrero, Mexico.. BMC Med Res Methodol 2020;20:125.

59 Dion A, Robert É, Sarmiento I, et al. A guideline for the weight of evidence, 2019CIET-PRAM, Department of Family Medicine, McGill University. Available: https://ciet.org/weight of evidence/ [Accessed 2020/10/22]

60 Borenstein M, Hedges LV. Effect size for meta-analysis. In: Cooper HM, Hedges LV, Valentine J, eds. Handbook of research synthesis and meta-analysis. New York: Russell Sage Foundation, 2019: 208-43. https://muse.jhu.edu/book/65827/

61 Papageorgiou El, Kontogianni A. Using fuzzy cognitive mapping in environmental decision making and management: a methodological primer and an application. International Perspectives on Global Environmental Change, 2012

62 Stylios D, Groumpos PP, Georgopoulos VC, et al. Fuzzy cognitive MAP approach to process control systems Chrysostomos. J Adv Comput Intell Intell Inform 1999;3:409-17.

63 Harris ZS. Discourse analysis. Language 1952;28:1.

64 Andersson N, Mitchell S. Epidemiological geomatics in evaluation of mine risk education in Afghanistan: introducing population weighted raster maps. Int J Health Geogr 2006;5:1.

65 Sibley L, Ann Sipe T, Sipe TA. What can a meta-analysis tell us about traditional birth attendant training and pregnancy outcomes? Midwifery 2004:20:51-60.

66 Sibley L, Sipe TA, Koblinsky M. Does traditional birth attendant training improve referral of women with obstetric complications: a review of the evidence. Soc Sci Med 2004:59:1757-68. 
67 Sibley LM, Sipe TA, Koblinsky M. Does traditional birth attendant training increase use of antenatal care? A review of the evidence. $J$ Midwifery Womens Health 2004;49:298-305.

68 Sibley LM, Sipe TA, Brown CM, et al. Traditional birth attendant training for improving health behaviours and pregnancy outcomes. Cochrane Database Syst Rev 2007:CD005460.

69 Darmstadt GL, Lee ACC, Cousens S, et al. 60 million non-facility births: who can deliver in community settings to reduce intrapartumrelated deaths? Int J Gynaecol Obstet 2009;107:S89-112.

70 Lawn JE, Lee ACC, Kinney M, et al. Two million intrapartum-related stillbirths and neonatal deaths: where, why, and what can be done? Int J Gynaecol Obstet 2009;107:S5-19.

71 Lawn JE, Kinney M, Lee ACC, et al. Reducing intrapartum-related deaths and disability: can the health system deliver? Int J Gynaecol Obstet 2009;107:S123-42.

72 Hofmeyr GJ, Haws RA, Bergström S, et al. Obstetric care in lowresource settings: what, who, and how to overcome challenges to scale up? Int J Gynaecol Obstet 2009;107:S21-45.

73 Wall SN, Lee ACC, Niermeyer S, et al. Neonatal resuscitation in lowresource settings: what, who, and how to overcome challenges to scale up? Int J Gynaecol Obstet 2009;107:S47-64.

74 Lee ACC, Lawn JE, Cousens S, et al. Linking families and facilities for care at birth: what works to AVERT intrapartum-related deaths? Int J Gynaecol Obstet 2009;107:S65-88.

75 Kidney E, Winter HR, Khan KS, et al. Systematic review of effect of community-level interventions to reduce maternal mortality. BMC Pregnancy Childbirth 2009;9:2.

76 Byrne A, Morgan A. How the integration of traditional birth attendants with formal health systems can increase skilled birth attendance. Int $J$ Gynaecol Obstet 2011;115:127-34.

77 Wilson A, Gallos ID, Plana N, et al. Effectiveness of strategies incorporating training and support of traditional birth attendants on perinatal and maternal mortality: meta-analysis. BMJ 2011;343:d7102.

78 Glenton C, Colvin CJ, Carlsen B, et al. Barriers and facilitators to the implementation of lay health worker programmes to improve access to maternal and child health: qualitative evidence synthesis. In:
Glenton C, ed. Cochrane database of systematic reviews. Chichester, UK: John Wiley \& Sons, Ltd, 2013.

79 Vieira C, Portela A, Miller T, et al. Increasing the use of skilled health personnel where traditional birth attendants were providers of childbirth care: a systematic review. PLoS One 2012;7:e47946.

80 Bohren MA, Hunter EC, Munthe-Kaas HM, et al. Facilitators and barriers to facility-based delivery in low- and middle-income countries: a qualitative evidence synthesis. Reprod Health 2014;11:71.

81 Lassi ZS, Das JK, Salam RA, et al. Evidence from community level inputs to improve quality of care for maternal and newborn health: interventions and findings. Reprod Health 2014;11:S2.

82 Mangham-Jefferies L, Pitt C, Cousens S, et al. Cost-effectiveness of strategies to improve the utilization and provision of maternal and newborn health care in low-income and lower-middle-income countries: a systematic review. BMC Pregnancy Childbirth 2014;14:243.

83 World Health Organization. WHO recommendations on health promotion interventions for maternal and newborn health 2015. Geneva, 2015. Available: https://www.who.int/maternal_child_ adolescent/documents/health-promotion-interventions/en/ [Accessed 29 Jan 2019].

84 World Health Organization. WHO recommendations on maternal health: guidelines approved by the WHO guidelines review Committee. Geneva, 2017. Available: http://who.int/tb/features_ archive/factsheet_xpert.pdf [Accessed 13 Dec 2019].

85 Lassi ZS, Middleton PF, Bhutta ZA, et al. Strategies for improving health care seeking for maternal and newborn illnesses in low- and middle-income countries: a systematic review and meta-analysis. Glob Health Action 2016;9:31408.

86 Miller T, Smith $\mathrm{H}$. Establishing partnership with traditional birth attendants for improved maternal and newborn health: a review of factors influencing implementation. BMC Pregnancy Childbirth 2017;17:1-10.

87 World Health Organization. Department for maternal, newborn $\mathrm{C}$ and a health (WHO/MCA). MASCOT/Wotro map of maternal health research (database), 2013. Available: http://eppi.ioe.ac.uk/ webdatabases4/Intro.aspx?ID=11 [Accessed 12 Dec 2019]. 